\title{
RELATIONS BETWEEN PARAMETERS OF STEP-TRACKING MOVEMENTS AND SINGLE CELL DISCHARGE IN THE GLOBUS PALLIDUS AND SUBTHALAMIC NUCLEUS OF THE BEHAVING MONKEY $^{1}$
}

\author{
APOSTOLOS P. GEORGOPOULOS, ${ }^{2}$ MAHLON R. DELONG, AND MICHAEL D. CRUTCHER ${ }^{3}$ \\ Departments of Neuroscience, Neurology, and Physiology, The Johns Hopkins University School of Medicine, \\ Baltimore, Maryland 21205
}

Received July 20, 1982; Revised February 22, 1983; Accepted March 7, 1983

\begin{abstract}
We describe the relations between the direction, amplitude, and velocity of step-tracking arm movements and the frequency of single cell discharge in the external (GPe) and internal (GPi) segments of the globus pallidus and the subthalamic nucleus (STN) of the behaving monkey. Statistically significant relations to the direction, amplitude, and peak velocity of the movement were found in all structures studied predominantly during the movement but also during the reaction time. For movements in a particular direction, the discharge rate was frequently a linear function of the movement amplitude and/or peak velocity. The slopes of this relation differed for different cells and comprised both positive and negative values. STN differed from both GPe and GPi in that (a) a larger proportion of neurons in STN showed significant relations to the direction of movement and $(b)$ the onset times of changes in neural activity related to movement occurred earlier in STN than in GPe or GPi.

The results of these studies suggest that cells in GPe, GPi, and STN may be involved in the control of movement parameters. Loss of the basal ganglia output related to the amplitude or velocity of movement might account for the impairments of step movements observed in Parkinsonian patients. On the other hand, deranged or excessive output related to amplitude or velocity control might result in the excesses of movement observed in other disorders, such as chorea and hemiballismus. These studies also provide direct evidence that the STN exerts a specific influence on basal ganglia output related to the control of movement parameters.
\end{abstract}

A major abnormality in diseases of the basal ganglia is motor dysfunction. In Parkinson's disease, patients often have difficulty both in the initiation and in the execution of movements, which are slowed, especially when movements of large amplitudes have to be made (Draper and Johns, 1964; Flowers, 1975). On the other hand, involuntary movements of large amplitude are observed in hemiballismus, another disorder of the basal ganglia. These clinical findings suggest that the basal ganglia play a rather specific role in the control of certain aspects of movement. However, the precise function of

\footnotetext{
${ }^{1}$ This work was supported by United States Public Health Service Grants NS 15417, NS 06828, and NS 07226.

${ }^{2}$ To whom correspondence should be addressed at the Philip Bard Laboratories of Neurophysiology, Department of Neuroscience, The Johns Hopkins University, School of Medicine, $725 \mathrm{~N}$. Wolfe Street, Baltimore, MD 21205.

${ }^{3}$ Present address: Division of Neurobiology and Behavior, Columbia University, CPS, 630 W. 168th Street, New York, NY 10032.
}

these nuclei in the normal subject is not well understood. A better understanding of the relation of neuronal discharge to specific movement parameters would provide important clues concerning the contribution of these nuclei to movement. Several studies in behaving monkeys have documented relations between certain parameters of limb movement and single cell discharge in the basal ganglia. In particular, significant relations have been found between cell discharge and both the direction of movement (DeLong, 1971; Liles, 1979; Aldridge et al., 1980; Crutcher and DeLong, 1981) and muscular force (Branch et al., 1980; Crutcher and DeLong, 1981; Liles, 1981). In addition, differences in cell discharge during fast ballistic movements versus slow ramp movements have been described (DeLong, 1973; DeLong and Strick, 1974).

A major objective of this investigation was to study quantitatively the relations between the amplitude and direction of limb movements and the discharge of single 
cells in the basal ganglia. We selected the globus pallidus (GP) for study because the cells in the internal segment of GP (GPi) give rise to the major output from the basal ganglia. We also studied the subthalamic nucleus (STN) because, anatomically and functionally, the STN appears to exert a major controlling influence over GP. Lesions of the STN in humans (Whittier, 1947) and monkeys (Whittier and Mettler, 1949; Carpenter et al., 1950) result in one of the most violent motor disorders (hemiballismus). Yet, no electrophysiological studies of its relation to movement have been undertaken in the behaving monkey. Preliminary results of these studies have been presented (DeLong and Georgopoulos, 1979; Georgopoulos and DeLong, 1979)

\section{Materials and Methods}

\section{General}

Two rhesus monkeys, weighing 4 to $6 \mathrm{~kg}$, were used in these experiments. The animals were trained to perform the visuomotor arm-tracking task described below. After completion of training, a recording chamber was positioned, under general anesthesia, over a round opening of the skull and held in place with acrylic. For recordings in the GP, the axis of the chamber was aimed stereotaxically at the center of GP $(\mathrm{A} 12, \mathrm{~L} 6, \mathrm{H} 6)$ at an angle of $50^{\circ}$ from vertical. For recordings in STN the recording chamber was positioned vertically at A7. A Narishige microdrive was used to lower glass-coated, platinum-iridium microelectrodes of 0.5 to 1.5 megohm impedance (at 1000 $\mathrm{Hz}$ ) through the dura and into the brain. Penetrations were separated by $1 \mathrm{~mm}$. During experimental sessions the head of the animal was immobilized mechanically. Only single units isolated from background noise and meeting the criteria for extracellular recordings from cell bodies were accepted for study. Once a neuron was thus isolated, a detailed examination of the animal was carried out by at least two observers to determine $(a)$ whether the cell activity was related to movements of a body part and, if so, to which one; and $(b)$ the cell's response to passive manipulations of skin, muscles, joints and deep tissues with the animal relaxed. If related to arm movements in the examination, the cell's activity was recorded while the monkey performed the task.

A record was kept of the depth at which each cell was isolated along the entire length of each penetration, from the first cells recorded in the upper layers of the cerebral cortex to the last cells recorded below GP or STN. Entry of the electrode into the external segment of GP $(\mathrm{GPe})$ was indicated reliably by the abrupt appearance of high discharge rate neurons typical of this nucleus (DeLong, 1971; Anderson, 1977). The depth at which the first pallidal activity was recorded in each penetration provided a reliable reference point for the subsequent plotting of neurons along the penetration. Electrolytic marking lesions were made during the final penetrations in order to confirm histologically the location of recording sites.

\section{Histology and reconstruction of penetrations}

At the end of each experiment the animal was anesthetized deeply with an overdose of pentobarbital and then perfused successively with isotonic saline and buffered formalin. The brain was embedded in celloidin and sectioned in the coronal plane every $25 \mu$, and the sections were stained with thionin. Only data from penetrations identified histologically within the GP and STN are included in this study.

\section{Behavioral paradigm}

The monkey sat in a primate chair and grasped a vertically mounted manipulandum in front of him. The manipulandum consisted of a light-weight, low-friction handle which the monkey moved from side to side or in a push-pull direction. The display consisted of two rows of light-emitting diodes (LEDs) arranged in two horizontal rows, one below the other. Each row contained 128 LEDs and was $32 \mathrm{~cm}$ long. The illuminated LED of the upper row indicated the target position; the illuminated LED of the lower row corresponded to the current position of the handle. The illumination was enhanced when the two LEDs were aligned within a positional window. The animal was required to move the handle so as to align the lower LED with the upper LED.

A trial began by turning on the target LED at an initial (starting) position. The animal had to move the manipulandum to align the handle position LED with that of the target LED and hold in that position for at least 2 sec. The initial LED was then turned off while a new (target) LED was lighted, and the animal had to move the handle and align its LED below the new target LED. The movements were either side to side or push-pull in different runs. A liquid reward was delivered after the animal held the handle for at least $0.5 \mathrm{sec}$ at the target position.

\section{Design of the experiments}

The major objective of this study was to quantify the relations between the frequency of single cell discharge and the direction and amplitude of movement. These two movement parameters were varied differently in two experimental designs ( $A$ and $B$ ) as follows. In the first design (A) both the direction and the amplitude of movement were varied within the same run. Movements started from the same point and were of opposite directions. Two movement amplitudes (25 and $37.5 \mathrm{~mm}$ ) for each direction were tested. The resulting four directionamplitude combinations were presented in a completely randomized design. The relations between the frequency of neuronal discharge and these two movement parameters were evaluated using a two-way analysis of variance. In a subsequent design (B) three movement amplitudes were used in separate runs for each of the two directions. These amplitudes were of a wider range $(25,62.5$, and $100 \mathrm{~mm}$ ) and were presented in a randomized block design (Cochran and Cox, 1957). The relations between movement amplitude and frequency of cell discharge were analyzed using a linear regression analysis.

\section{Data analysis}

The data analysis described below was performed on a trial-by-trial basis. Each trial was divided into epochs using behavioral events as follows (Fig. 1). (1) Control 


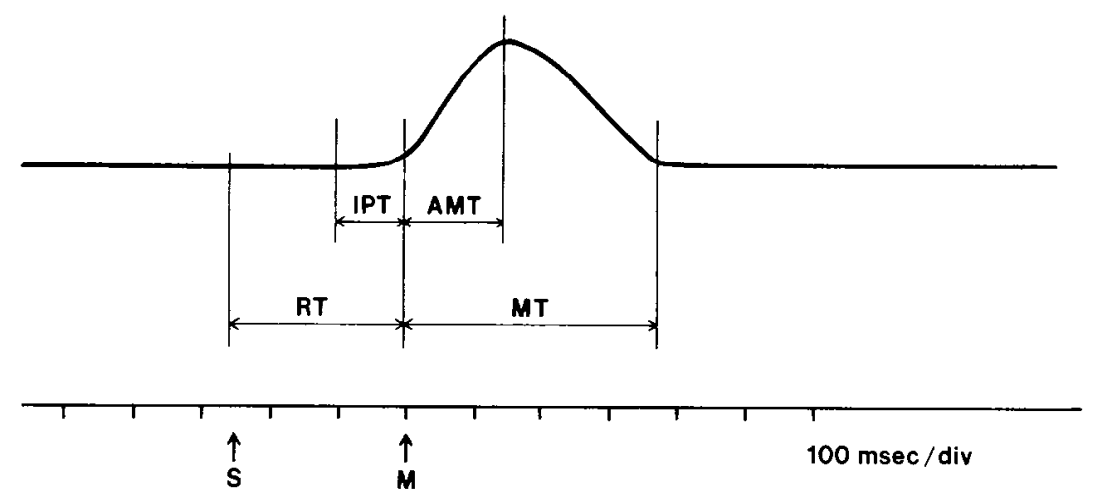

Figure 1. Division of a trial in the step-tracking task into epochs. The heavy line represents the velocity record of a single trial. $R T$, reaction time; $M T$, movement time; $I P T$, immediate premovement time; $A M T$, accelerating movement time; $M$, onset of movement; $S$, appearance of the target stimulus. For explanation see the text.

period (CP) was the time from the moment that the monkey aligned the handle in the starting position until the appearance of the target stimulus (period preceding stimulus, $S$, in Fig. 1). (2) Reaction time (RT) was the time that elapsed from the presentation of the target until the onset of movement, as determined from the velocity record. An immediate premovement time (IPT) was distinguished which comprised the $100 \mathrm{msec}$ preceding movement onset; during this time most of the EMG changes began to occur. (3) Movement time (MT) was the time from the beginning of the movement until its end, as determined from the velocity record. An accelerating movement time (AMT) was distinguished, which extended from the onset of movement to the time of occurrence of the peak velocity. (4) Target holding time (THT) was the time from the end of the movement to the delivery of reward (period following end of MT in Fig. 1). The frequency of discharge (impulses per second) of each cell during each of the above epochs for each trial was calculated. Changes in discharge from the firing rate during the control period were evaluated using a paired Student's $t$ test.

The onset times of changes in neuronal discharge were determined as follows. The control period was subdivided into 20 -msec bins, and the average per bin discharge rate was calculated. Histograms of 20 -msec bins were aligned to the onset of movement and plotted as differences between each bin and the mean discharge rate per bin, observed during the control period. A consistent change in discharge was deemed to occur when the rate of at least four consecutive bins were above (or below) the mean control per bin firing rate. The first bin showing the change was taken as the onset time of the neuronal response.

\section{Data acquisition}

A PDP-11/10 laboratory minicomputer was used to control and monitor the behavior of the animal and to collect analog data and neuronal events. The behavioral control consisted of turning on the target lights, monitoring the position of the manipulandum, and counting elapsed times following certain behavioral events.

The manipulandum was coupled to a potentiometer whose output indicated the position of the handle. The output voltage of the potentiometer was differentiated with an analog circuit to provide velocity and acceleration signals. All of the analog voltages (position, velocity, and acceleration of the handle, and electromyograms) were fed to analog-to-digital converters which were sampled by the computer at $100 / \mathrm{sec}$. The neuronal spike events were collected as interspike intervals with a resolution of $0.1 \mathrm{msec}$. Behavioral, analog, and neuronal data were collected for each trial.

\section{Electromyographic studies}

The electromyographic activity of muscles acting at the shoulder, elbow, and wrist, as well as that of axial muscles, was recorded using intramuscular, fine copper wires. Muscles studied included the triceps (lateral and long heads), biceps, brachialis, teres major, deltoid, pectoralis major, trapezius, supra- and infraspinatus, subscapularis, flexors and extensors of the wrist, and the deep thoracic and cervical paraspinous muscles. The raw EMG activity was amplified, rectified, and filtered before being fed to the computer. The EMG recordings were carried out in sessions separate from the neuronal recordings.

\section{Results}

All of the cells included in this study were related to arm movements made by the animal during examination outside the behavioral task. Eighty-seven neurons in $\mathrm{GPe}, 36$ in GPi, and 29 in STN were studied.

\section{Description of movements and electromyographic activity}

Movements had a dome-shaped velocity curve, i.e., they were characterized by an accelerating and decelerating phase (Fig. 2). Amplitude of movement and peak velocity were highly correlated $(\mathrm{r}=0.989 ; \mathrm{Fig} .3)$. Most EMG changes began during the IP'T. The average earliest EMG changes occurred at about $80 \mathrm{msec}$ before movement onset. The paraspinous muscles were inactive in the task.

\section{Discharge patterns in the control period}

Two types of cell discharge in GPe were observed during the control period: cells with high discharge frequency with pauses and cells with low discharge fre- 


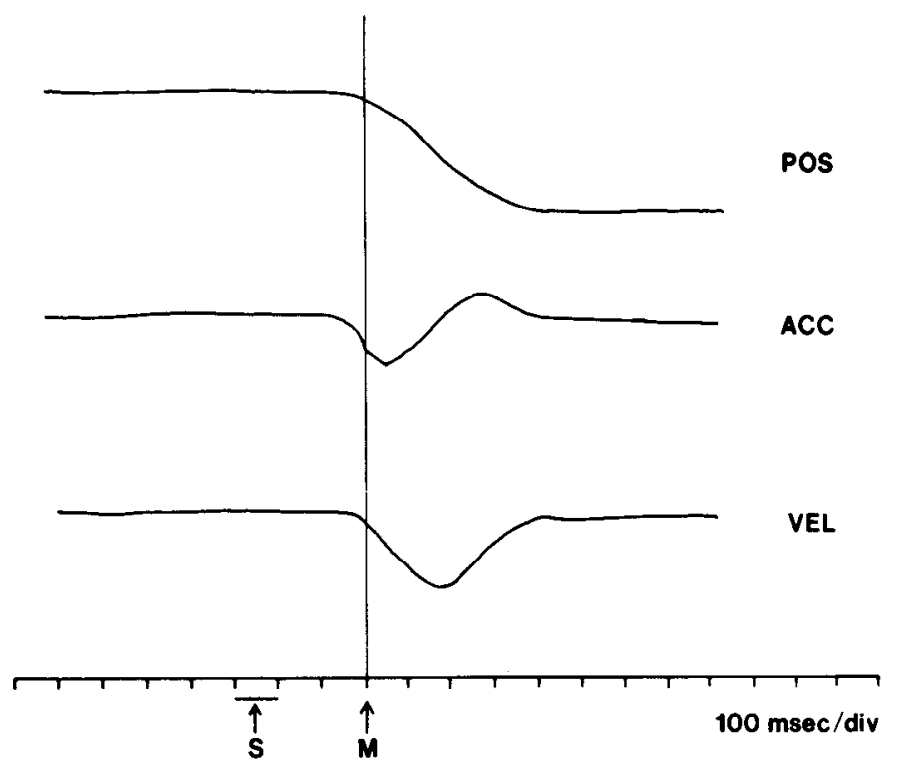

Figure 2. Average position ( $P O S$ ), velocity ( $V E L)$, and acceleration $(A C C)$ traces from 10 successive movements in the task. $M$, onset of movement; $S$, appearance of target stimulus. Horizontal bar $= \pm 1 \mathrm{SD}$.

quency with bursts. Their discharge rates were $71 \pm 31$ and $18 \pm 4$ impulses/sec (mean $\pm \mathrm{SD}$ ), respectively. In $\mathrm{GPi}$, cells discharged at a high frequency without pauses (79 \pm 22 impulses/sec), and in STN they discharged at lower rates $(23 \pm 12$ impulses/sec). The patterns of discharge in GPe and GPi described above during steady holding in the control period were similar to those described by DeLong (1971) during quiet wakefulness, with the exception that in the present study the pauses in GPe neurons were less frequent and of shorter duration.

\section{Relations to the direction of movement}

The relations between movement direction and the frequency of cell discharge were studied using experimental design A (see "Materials and Methods") in 62 cells in GPe, 22 in GPi, and 22 in STN. Cells in all three structures showed significant relations to the direction of movement (Table I), in that their frequency of discharge differed for different directions of movement. Examples are shown in Figure 4. Significant directional effects were observed most frequently during the AMT (Table I), although the effect was also present during the IPT. The average difference in discharge rate during the MT between movements of opposite directions but of the same amplitude was 23 impulses/sec in GPe, 30 impulses/sec in GPi, and 15 impulses/sec in STN; during the RT these differences were 24,20 , and 23 impulses/ sec in GPe, GPi, and STN, respectively.

\section{Relations to the amplitude and peak velocity of the movement}

These relations were studied in 25 cells in GPe, 14 in $\mathrm{GPi}$, and 7 in STN using a wide range of three movement amplitudes and a linear regression analysis (experimental design B, see "Materials and Methods"). It can be seen in Table II that significant relations between the frequency of cell discharge and the amplitude or peak velocity of movement were observed in a high proportion

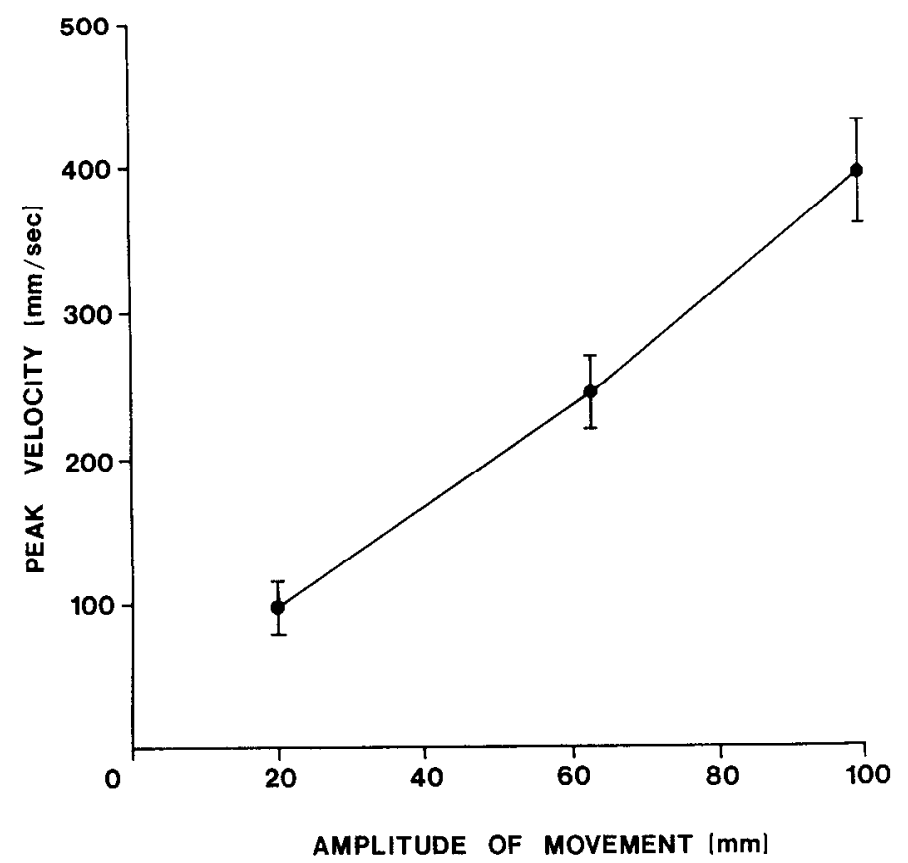

Figure 3. Relation between amplitude and peak velocity of movement. Means \pm SEM are plotted. $N=100$ movements for each amplitude. $\mathrm{r}=0.989$.

TABLE I

Percentages of neurons that showed significant relations to the direction of movement during various epochs ( $p<0.05, F$ test, analysis of variance)

\begin{tabular}{lccc}
\hline & $\begin{array}{c}\text { GPe } \\
(n=62)\end{array}$ & $\begin{array}{c}\text { GPi } \\
(n=22)\end{array}$ & $\begin{array}{c}\text { STN } \\
(n=22)\end{array}$ \\
\hline Reaction time & & & \\
$\quad$ Total RT & 13 & 14 & 32 \\
IPT & 23 & 31 & 69 \\
Movement time & & & \\
$\quad$ Total MT & 48 & 41 & 73 \\
$\quad$ AMT & 41 & 56 & 92 \\
\hline
\end{tabular}

of cells in all three structures studied. The incidence of these effects was highest in the MT, but the effects were also present in the IPT (Table II; see example in Fig. $5 B$ ).

In general, the frequency of cell discharge was a linear function of the movement amplitude, according to the equation

$$
D=K+b A
$$

where $D$ is the frequency of discharge, $K$ is a constant, $b$ is the regression slope, and $A$ is the amplitude of movement. Examples are shown in Figure 5. The values of the slopes $(b)$ obtained for every cell and for each of the two opposite directions of movement tested are shown in Figures 6,7 , and 8 for GPe, GPi, and STN, respectively. Dots within circles indicate that the slope was significantly different from $0(p<0.05$, the Student's $t$ test for the null hypothesis that $b=0$ ). It can be seen that these slopes comprised both positive and negative values and were highest during the AMT. For the neurons studied using experimental design A (see "Materials and Methods"), slopes of similar magnitude were obtained. However, due to the small range of the two movement amplitudes used in that design, the differences in cell discharge 


\section{STN}

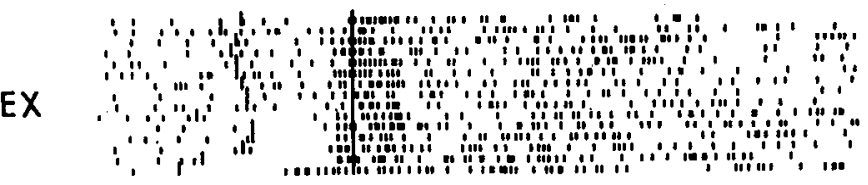

F L

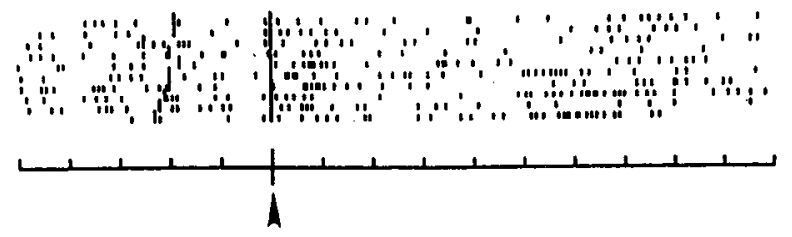

EX

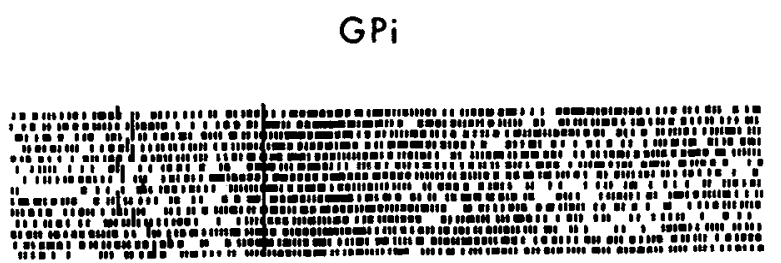

F L

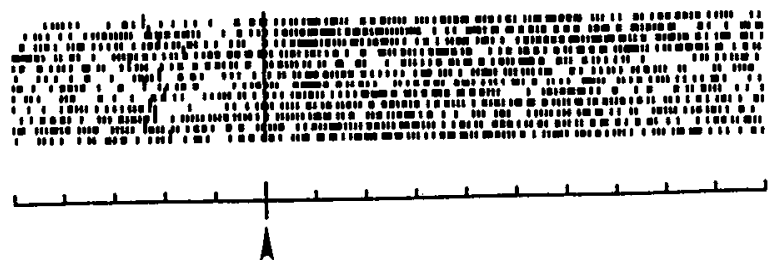

GPe

EX

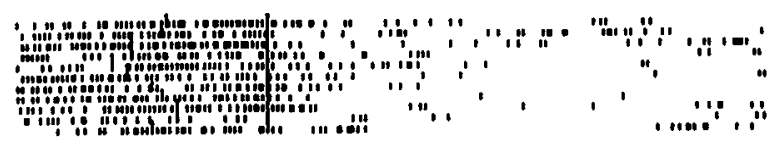

FL

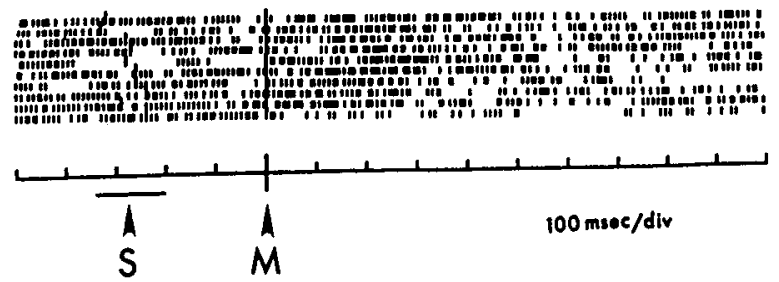

Figure 4. Rasters of the activity of single cells in GPe, GPi, and STN during flexion $(F L)$ and extension $(E X)$ movements. Cell activity differs between the two directions of movement.

observed under those circumstances attained statistical significance in only a few cases (Georgopoulos and DeLong, 1979).

A different question concerns the constant $K$ in equation 1. This is the $\mathrm{Y}$-intercept, that is, the discharge rate at zero movement amplitude predicted by the regression line. Interestingly, this expected value differed significantly from the rate actually observed during the control period, i.e., in the absence of movement (for examples, see Fig. 5).

The relations between cell discharge and peak velocity of movement resembled those described above for the movement amplitude. Thus, the frequency of discharge was a linear function of the peak velocity, and the slopes comprised both positive and negative values. This similarity was expected because peak velocity and movement amplitude were highly correlated (Fig. 3).

As a rule, the amplitude/peak velocity effects were seen in only one of the two directions of movement tested (Fig. 9B). In a few cells, however, similar relations were obtained for both movement directions, although at different levels of cell activity (Fig. 9A). Finally, in cells in which significant relations to movement amplitude and/ or peak velocity were not found, a significant change in discharge from the control rate was often observed. Examples are shown in Figure 10, $A$ and $B$. The magnitude and sign (increase, decrease) of such step changes were frequently related to the direction of movement.

\section{Onset times}

An increase of discharge as the first sign of change in neuronal activity occurred more frequently than a decrease. The increase/decrease ratio was 4.2 in GPe, 2.3 in $\mathrm{GPi}$, and 2.6 in STN. Table III, part A shows the percentages of increases and decreases in cell discharge which occurred (1) before the onset of movement, and (2) before the average earliest EMG changes (about 80 msec preceding movement onset). The median values of the distributions of cell onset times are given in Table III, part B. It can be seen that an appreciable percentage of the changes in cell activity in all structures studied preceded movement onset. STN led in time both GPe and GPi in all measures used, namely, in changes before movement and before earliest EMG changes and in median onset time. Finally, GPe tended to lead GPi in changes preceding movement onset and earliest EMG changes, but the median values of the distributions of onset times were the same in these two structures.

\section{Discussion}

The major objectives of this study, were first, to quantify the relations between single cell discharge in the hasal ganglia and parameters of movement and, second, to compare these relations between the structures chosen for study. A salient finding was that significant and similar relations to movement parameters were observed in all structures studied. This and the fact that significant relations were observed before the onset of, as well as during the movement indicate that the structures studied may participate in the control of movement parameters. We shall discuss these findings in the context of current views concerning the motor functions of the basal ganglia.

\section{Relations to the direction of movement}

A high proportion of cells in GPe, GPi, and STN discharged at different rates with movements in opposite 
TABIE II

Percentages of neurons that showed significant linear relations to the amplitude and peak velocity of movement in either direction $(p<0.05, F$ test, analysis of variance)

\begin{tabular}{|c|c|c|c|c|c|}
\hline \multicolumn{6}{|c|}{ Step Movement } \\
\hline & Amplitude & & & eak Veloci & \\
\hline $\begin{array}{c}\mathrm{GPe} \\
(n=25)\end{array}$ & $\begin{array}{c}\mathrm{GPi} \\
(n=14)\end{array}$ & $\begin{array}{c}\text { STN } \\
(n=7)\end{array}$ & $\begin{array}{c}\mathrm{GPe} \\
(n=25)\end{array}$ & $\begin{array}{c}\mathrm{GPi} \\
(n=14)\end{array}$ & $\begin{array}{c}\text { STN } \\
(n=7)\end{array}$ \\
\hline
\end{tabular}

\begin{tabular}{|c|c|c|c|c|c|c|}
\hline \multicolumn{7}{|l|}{ Reaction time } \\
\hline Total RT & 3 & 0 & 0 & 10 & 0 & 0 \\
\hline IPT & 21 & 36 & 29 & 24 & 14 & 14 \\
\hline \multicolumn{7}{|c|}{ Movement time } \\
\hline Total M'T & 66 & 79 & 57 & 59 & 71 & 57 \\
\hline AMT & 52 & 79 & 57 & 52 & 71 & 43 \\
\hline
\end{tabular}

directions. This directional effect was observed during both the reaction and movement time. These findings agree with earlier qualitative observations in GP (DeLong, 1971; Aldridge et al., 1980) and putamen (Liles, 1979), and with recent quantitative studies in the putamen (Crutcher and DeLong, 1981). The presence of directional effects in GP probably reflects the fact that the inputs to this structure from the putamen (DeLong and Strick, 1974; Liles, 1978, 1979; Crutcher and DeLong, 1981) and from the STN (this study) also show a relation to the direction of movement. The presence of directional relations in the putamen and STN could, in turn, be accounted for by the input to these structures from the cerebral cortex, since both precentral (Schmidt et al., 1975; Thach, 1978; Georgopoulos et al., 1982) and parietal (Kalaska et al., 1983) cortical colls show significant relations to the direction of movement. This information seems to be preserved in the motor thalamus, where a relation between cell discharge and direction of movement has also been observed (Strick, 1976; MacPherson et al., 1980; M. K. DeLong and A. P. Georgopoulos, unpublished observations).

\section{Relations to the amplitude of movement}

Significant relations between cell discharge and movement amplitude were observed during both the IPT and MT. The slopes calculated with the regression analysis differed in different cells and could take either positive or negative values. This means that there was no uniform relation between direction of change in neuronal discharge (increase or decrease) and the amplitude of movement: an increase in movement amplitude was associated in different cells with either an increase or a decrease in the frequency of discharge. It is noteworthy that these relations of neuronal discharge to movement amplitude became apparent when a wide range of amplitudes was used $(25 \mathrm{~mm}$ to $100 \mathrm{~mm}$; experimental design $\mathrm{B}$, see "Materials and Methods"). (These effects were not marked in initial experiments (Georgopoulos and DeLong, 1979), probably because of the small range of movement amplitudes employed in that study.)

There was frequently a sizable difference between rate of discharge at zero movement predicted from the regression equation and the actual discharge rate observed during the control period in which the animal was holding the manipulandum in a neutral position without moving. This discrepancy could have been the result of the presence of a nonlinear relation in the range of small movements (from 0 to $25 \mathrm{~mm}$ ). However, this explanation does not seem plausible for the following reasons. (a) In several cells there was no significant relation to the amplitude of movement (that is, the slope of the regression curve was not different from zero), and yet a step change from the control discharge rate was observed with movement. According to the above hypothesis one would have to assume that a steep slope existed for the small movements, which then became zero for the whole range of amplitudes above $25 \mathrm{~mm}$. This is unlikely. $(b)$ In other cases the direction of change in discharge from the control rate was opposite from that of the amplituderelated slope. For example, there was an increase in activity from the control rate with the small movement, yet the amplitude-related slope was negative (or vice versa). According to the above hypothesis this would mean that for these cells there were two slopes of opposite signs, one for the range of small movements and another for movements above $25 \mathrm{~mm}$. This again seems unlikely. A different interpretation, which we favor, would regard the neuronal responses to movement as the net result of various factors. The relevant factors in the present experiments were the direction and the amplitude of movement. It could be supposed that a step change in cell discharge was related to movement direction, and that this step change was further modulated according to the amplitude of movement. This is illustrated in the schematic diagram of Figure 11. These two effects could be controlled separately. For example, many neurons showed significant directional effects without amplitude effects, and others showed amplitude-related changes for only one direction of movement. Although the shape of the curve in the region of small movement amplitudes remains to be determined, this second interpretation is more general and seems more plausible.

The findings of this study may be relevant to the observation that patients with diseases of the basal ganglia frequently have difficulty in controlling the amplitude of their limb movements. For example, in patients with Parkinson's disease, single step movements of large amplitude are impaired; these movements fall short of the target (Flowers, 1975), which is then reached by a series of small-amplitude movements (Draper and Johns, 1964; Flowers, 1975). The mechanism of this phenome- 

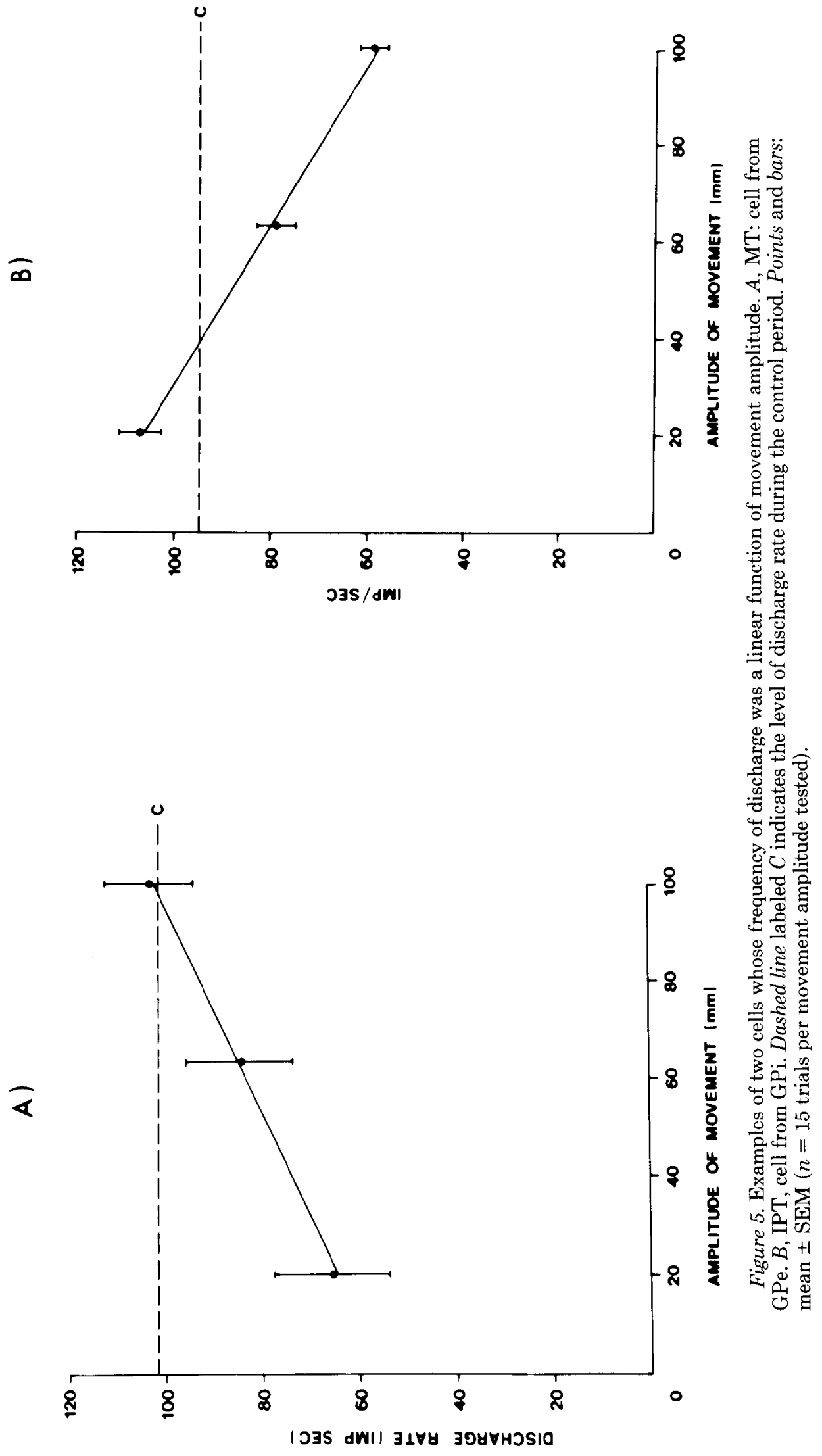


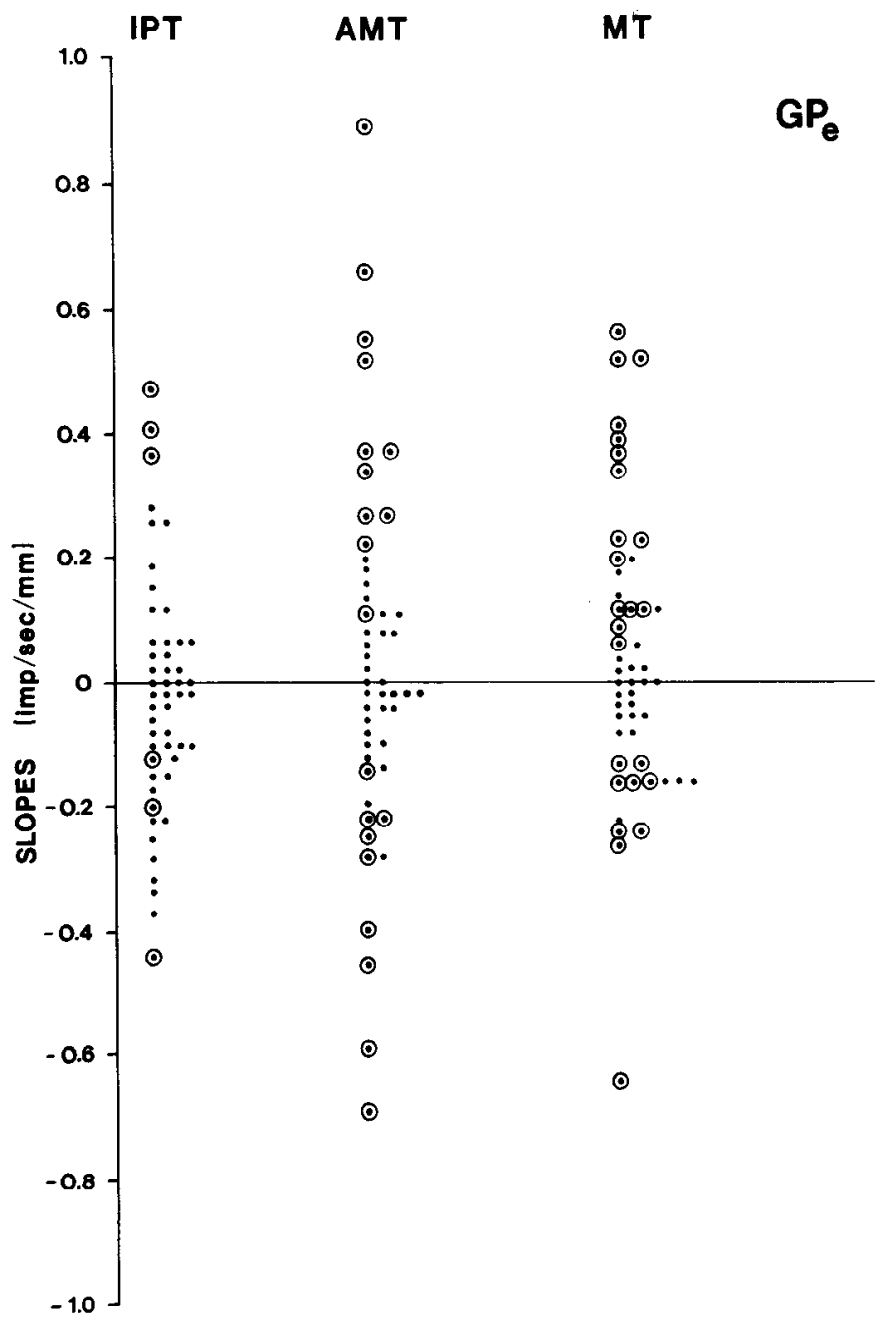

Figure 6 . Slopes of the relation between movement amplitude (millimeters) and cell discharge (impulses per second) during the IPT, AMT, and MT in GPe, as determined by linear regression. Circled dots represent slopes significantly different from $0(p<0.05)$; dots represent nonsignificant slopes. Data are from 25 cells studied in two movement directions. All slopes ( 25 cells $\times 2$ directions $=50$ points $)$ are shown.

non was partially elucidated recently by Hallett and Khoshbin (1980), who observed that Parkinsonian patients were unable to increase the amplitude of the agonist burst in step-tracking movements. Thus, largeamplitude movements were achieved by several smallamplitude steps. Loss or reduction of pallidal influence in the control of movement amplitude might account for the hypometric movements and the overall bradykinesia of Parkinsonian patients. On the other hand, excessive and deranged pallidal output may be responsible for the involuntary, large-amplitude movements of patients with hemiballismus.

\section{Relations to peak velocity of movement}

Cells that showed significant relations to the amplitude of movement also showed significant relations to the peak velocity of the movement. This was expected since the peak velocity was highly correlated with move-

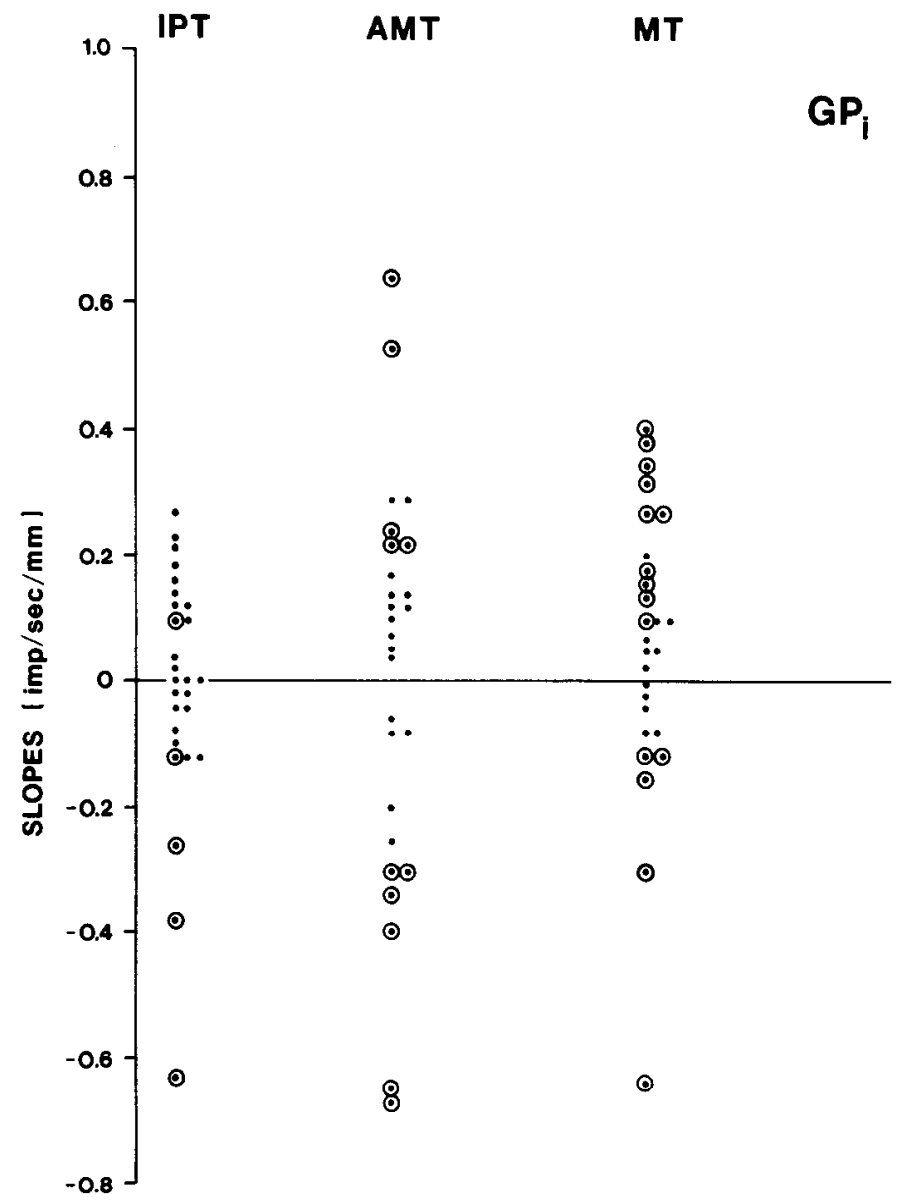

Figure 7. Slopes for GPi. Data are from 14 cells, 13 of which were studied in two movement directions. See legend to Figure 6 for explanation of the symbols. All slopes are shown (13 cells $\times 2$ directions $=26$, plus 1 cell for 1 direction $=27$ points).

ment amplitude (Fig. 3). The confounding of these two factors in the paradigm used does not allow differentiation between the amplitude or the peak velocity of the step movement as the main factor to which neuronal activity in the basal ganglia might be primarily related.

\section{Onset times of neuronal changes}

Most changes in neuronal discharge began after the first EMG changes, although changes in discharge in about one-fourth of the cells had begun before this time. These results are comparable to those observed in the putamen (Crutcher and DeLong, 1983) and in GP (Aldridge et al., 1980; Anderson and Horak, 1981; Fig. 7 in DeLong and Georgopoulos, 1981). Overall, changes in neuronal discharge seemed to occur a little later than in the motor cortex. For example, approximately 50\% of the cells in motor cortex changed activity before $80 \mathrm{msec}$ preceding movement (the approximate onset time of EMG changes) in reaction time tasks (Evarts, 1974; Thach, 1978); this percentage was $24 \%, 11 \%$, and $29 \%$ in GPe, GPi, and STN, respectively, in the present study. It appears, therefore, that neuronal activation in the motor cortex may precede activation in the movementrelated portions of the basal ganglia. This is not surpris- 


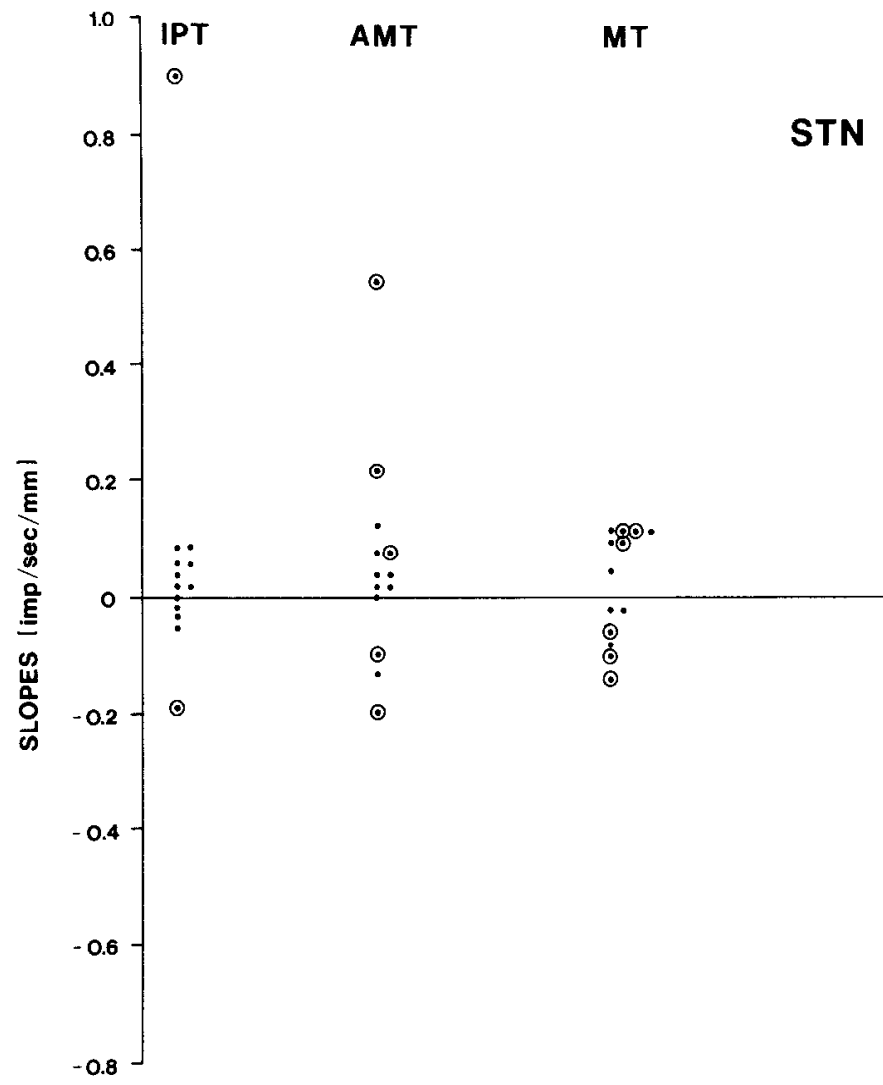

Figure 8. Slopes for STN. Data are from seven cells, six of which were studied in two movement directions. See legend to Figure 6 for explanation of the symbols. All slopes are shown $(6$ cells $\times 2$ directions $=12$, plus 1 cell for 1 direction $=13$ points).

ing because a major input to these portions of the basal ganglia comes from the motor cortex. Information from the cortex could then be processed through the basal ganglia and returned to the precentral motor areas, based on the known anatomical connections (see DeLong and Georgopoulos, 1981 for a review). In this respect, it is interesting that microstimulation of the GP slows the ensuing movement mainly when delivered just before movement, i.e., after the first changes in EMG activity but prior to movement onset (Horak and Anderson, 1980). Moreover, lesions (Horak and Anderson, 1980) and cooling (Hore and Villis, 1980) of GP result in slowing of movements without affecting reaction times. Together, these findings indicate that a contribution of the basal ganglia to motor function might be related to a facilitating action on motor cortical populations, a role similar to that proposed by Denny-Brown and Yanagisawa (1976) and Hallett and Kohshbin (1980) on other grounds.

\section{Differences between structures studied}

One objective of this investigation was to compare the activity of arm-related cells in three basal ganglia structures (GPe, GPi, and STN) in the same task. The structures studied are linked anatomically in a well defined way: GPe projects to STN, which then projects to both
GPe and GPi. GPi thus receives information from GPe through STN. Of course, $\mathrm{GPe}$ and $\mathrm{GPi}$ also receive projections from the striatum. We sought to gain information about the processing along the loop from GPe to STN to GPi and, if possible, to quantify the interstructural relations, insofar as movement is concerned.

A clear difference between the structures studied was the rate and pattern of cell discharge during the control period. Previous observations (DeLong, 1971) about the pattern and rates of tonic activity in GPe and GPi were confirmed in the present study. Thus, two main types of tonic firing patterns were observed in GPe: one (most frequent) with a high discharge rate interrupted by pauses of varying duration, and another (less frequent) with low average discharge rate and very high frequency bursts of short duration. Good relations in the task were seen for both types of cells. In GPi, cells had a high frequency, relatively continuous pattern of activity with frequent brief bursts. Cells in STN also discharged tonically but at lower rates. In a recent study, however, it was reported that pallidal cells did not discharge spontaneously in the resting animal (Iansek and Porter, 1980). It is difficult to reconcile this finding with the present and earlier studies from this laboratory (DeLong, 1971; DeLong and Strick, 1974) and others (Matsunami and Cohen, 1975; Anderson, 1977; Filion, 1979; Aldridge et al., 1980) in which the high tonic rates of pallidal cells have been observed under similar conditions.

It is noteworthy that the quantitative relations of the cell activity to movement were very similar in all three structures studied. Thus, cells in these structures showed direction-related effects and amplitude-related effects. The percentage of cells that showed directional effects was higher in STN than in GPe or GPi. On the other hand, the relations to the amplitude of movement were stronger in GPe and GPi, as evidenced by the higher values of the regression slopes in these two structures. The magnitude of changes from the control period were very similar in the three structures, although the percentage changes were higher in the STN.

Two interesting findings of the present study were the strong relations to movement observed for STN neurons and the earlier changes in discharge of STN as compared to GP neurons. These findings may be due to the direct projections from the motor cortex to the STN in the monkey (Petras, 1969; Hartmann-von Monakow et al., 1978). In the light of these studies, it is interesting to speculate on the role of the STN in primates. Lesioning of the STN results in the well known syndrome of hemiballismus in humans (Whittier, 1947) and in choreoid dyskinesia in the monkey (Whittier and Mettler, 1949; Carpenter et al., 1950). Since the output of STN is directed to GPi and since subsequent lesions in GPi abolish these involuntary movements, the dyskinesias are postulated to result from release of GP neurons from the controlling influence of the STN. It is noteworthy that dyskinesias following STN lesions have only been observed in primates, and, moreover, only in primates have projections from the motor cortex to the STN been found. It would appear that, with the development of sophisticated use of the limbs in primates, a new, addi- 

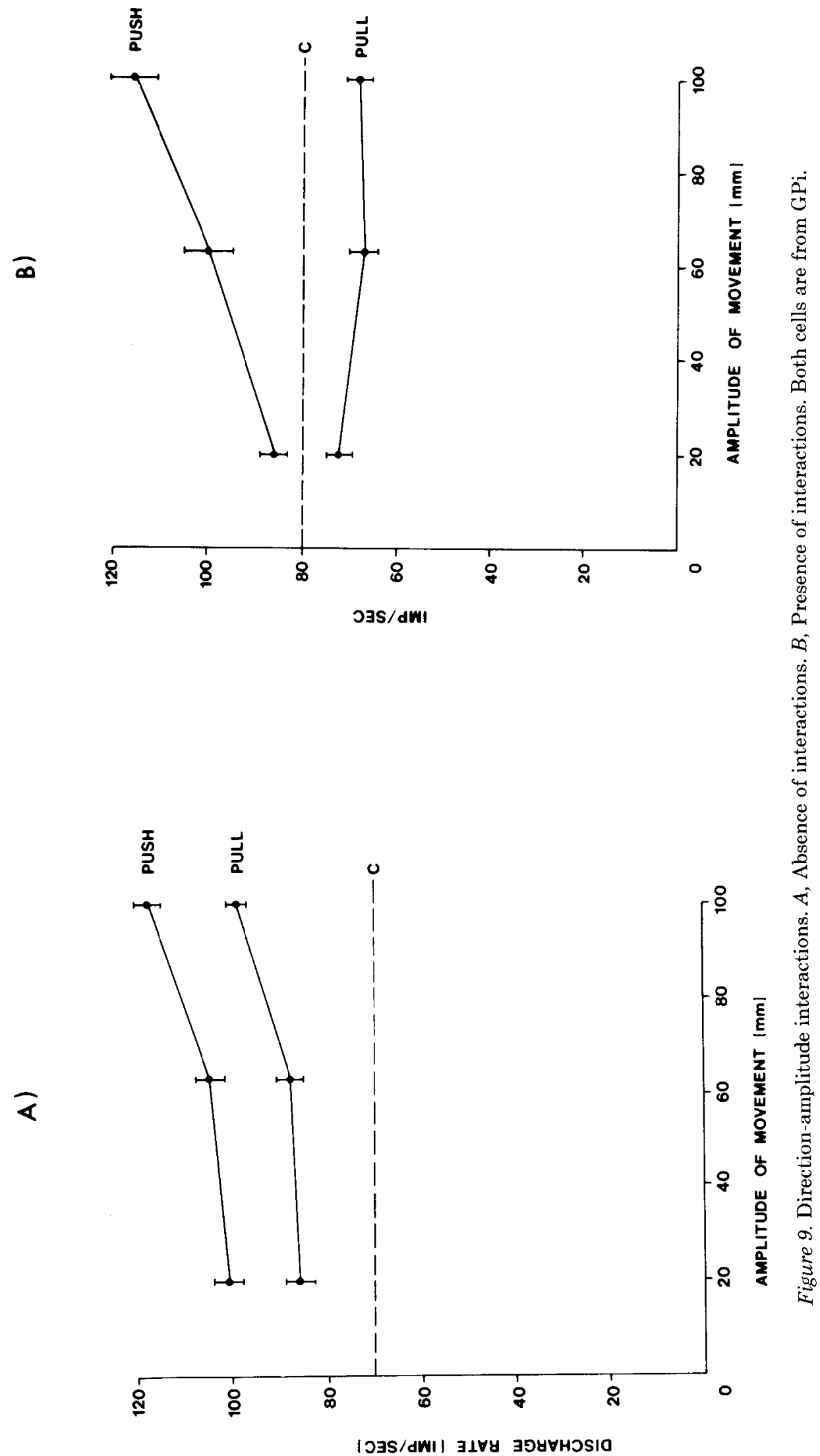


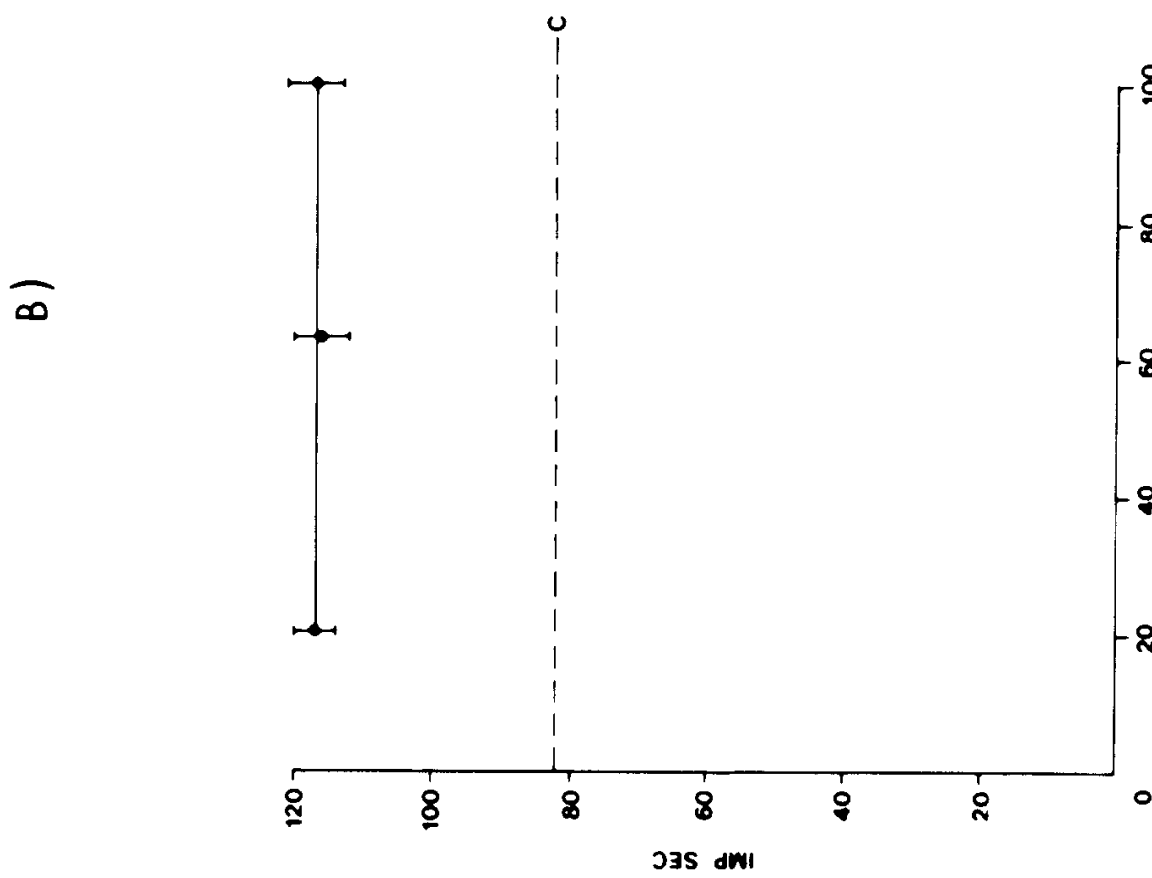

$\overline{4}$
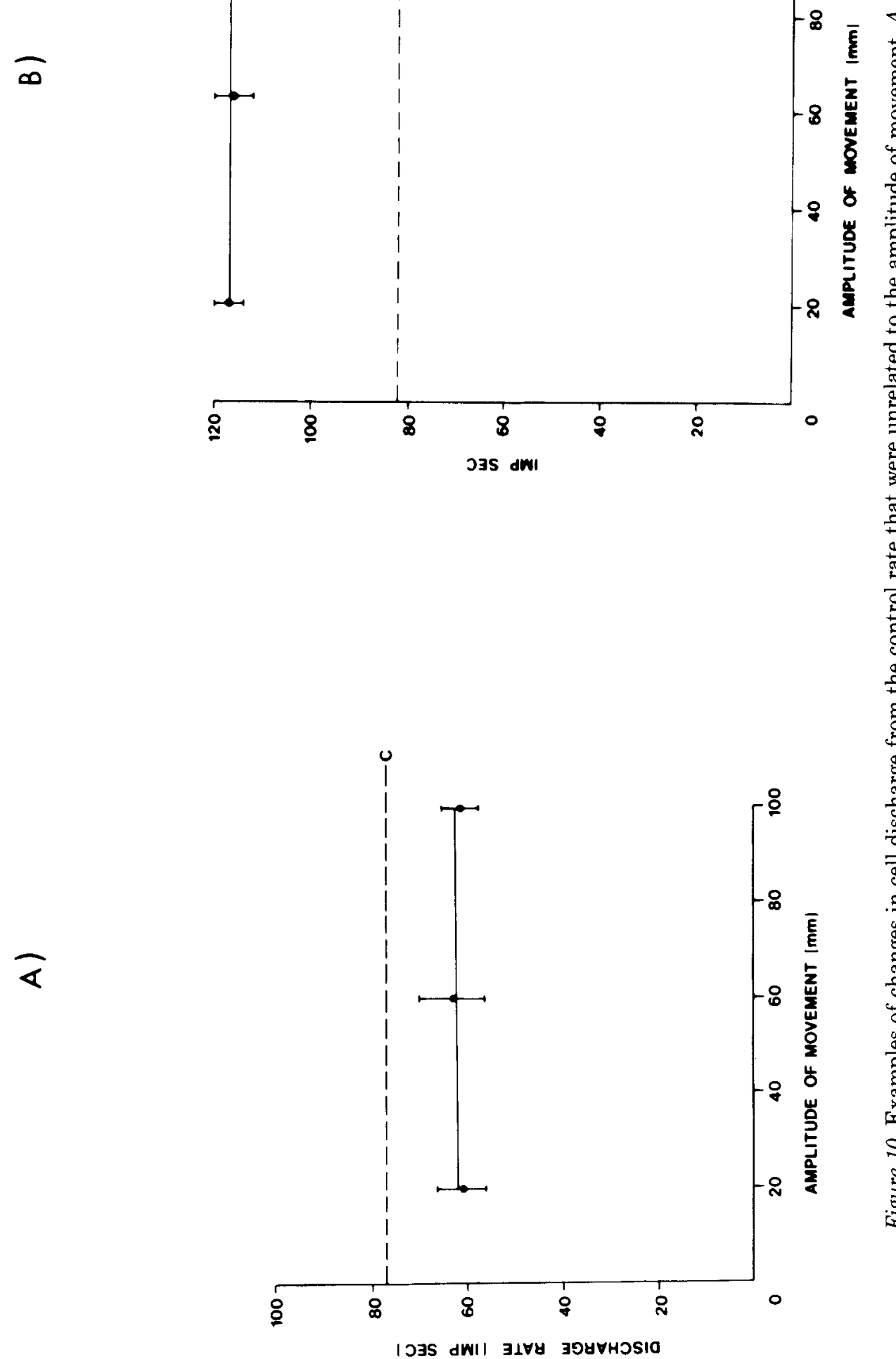

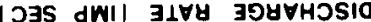




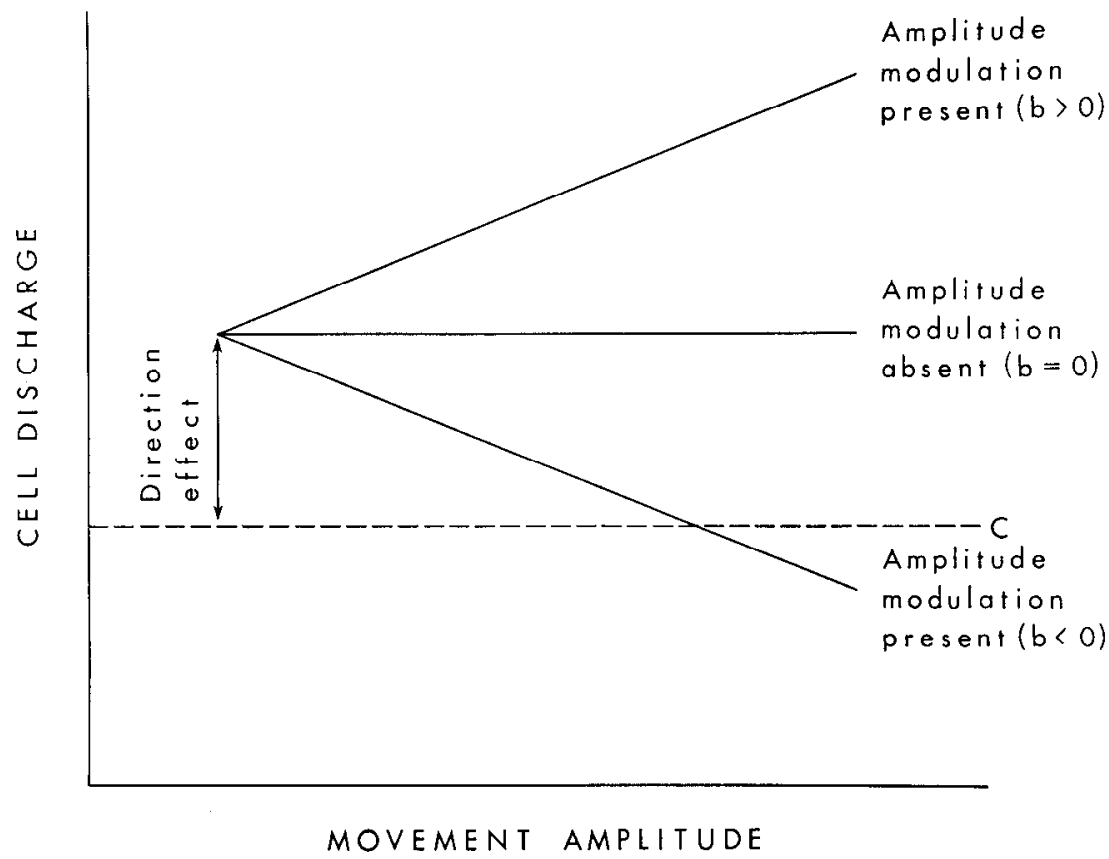

Figure 11. Schematic diagram illustrating the idea that single cell discharge in GP and STN may reflect $(a)$ a movement direction-related step change and $(b)$ a superimposed movement amplitude-related modulation.

TABLE III

A. Percentages of increases and decreases in cell discharge that occurred in the periods stated

\begin{tabular}{|c|c|c|}
\hline & $\begin{array}{c}\text { Increases } \\
\%\end{array}$ & $\begin{array}{c}\text { Decreases } \\
\%\end{array}$ \\
\hline \multicolumn{3}{|l|}{ GPe } \\
\hline $\begin{array}{l}\text { Before movement onset } \\
\text { (before average earliest } \\
\text { EMG changes) }\end{array}$ & (24) & (25) \\
\hline After movement onset & 52 & 51 \\
\hline Total & $\overline{100}$ & $\overline{100}$ \\
\hline \multicolumn{3}{|l|}{ GPi } \\
\hline $\begin{array}{l}\text { Before movement onset } \\
\text { (before average earliest } \\
\text { EMG changes }\end{array}$ & (11) & 26 \\
\hline After movement onset & 62 & 74 \\
\hline Total & $\overline{100}$ & $\overline{100}$ \\
\hline \multicolumn{3}{|l|}{ STN } \\
\hline $\begin{array}{l}\text { Before movement onset } \\
\text { (before average earliest } \\
\text { EMG changes) }\end{array}$ & (29) & 50 \\
\hline After movement onset & 25 & 50 \\
\hline Total & $\overline{100}$ & $\overline{100}$ \\
\hline
\end{tabular}

B. Median onset times of changes in cell discharge from beginning of

\begin{tabular}{lccc}
\multicolumn{3}{c}{ movement $^{a}$} \\
\hline & Increases & Decreases \\
\hline & & msec & \\
GPe & +10 & & +16 \\
GPi & +10 & +16 \\
STN & -50 & -50
\end{tabular}

${ }^{a}-$, before movement onset; + , after movement onset.

tional control of the basal ganglia by the motor cortex might have evolved. This control could be provided by the direct influence of the motor cortex on the subthalamic nucleus, a key structure controlling the output nuclei of the basal ganglia. In that light, then, subthalamic dyskinesia (hemiballismus), which is peculiar to primates, might be regarded as the outcome of disconnecting the basal ganglia from the newly acquired motor cortical control via the STN.

\section{References}

Aldridge, J. W., R. J. Anderson, and J. T. Murphy (1980) Sensory-motor processing in the caudate nucleus and globus pallidus: A single-unit study in behaving primates. Can. J. Physiol. Pharmacol. 58: 1192-1201.

Anderson, M. E. (1977) Discharge patterns of basal ganglia neurons during active maintenance of postural stability and adjustment to chair tilt. Brain Res. 143: 325-338.

Anderson, M. E., and F. B. Horak (1981) Changes in firing of pallidal neurons during arm reaching movements in a reaction time task. Soc. Neurosci. Abstr. 7: 741.

Branch, M. H., M. D. Crutcher, and M. R. DeLong (1980) Globus pallidus: Neuronal responses to arm loading. Soc. Neurosci. Abstr. 6: 272.

Carpenter, M. B., J. R. Whittier, and F. A. Mettler (1950) Analysis of choreoid hyperkinesia in the rhesus monkey: Surgical and pharmacological analysis of hyperkinesia resulting from lesions in the subthalamic nucleus of Luys. J. Comp. Neurol. 92: 293-331.

Cochran, W. G., and G. M. Cox (1957) Experimental Designs, Ed. 2, John Wiley \& Sons, New York.

Crutcher, M. D., and M. R. DeLong (1981) Relation of putamen neuronal discharge to direction of movement or pattern of muscular activity. Soc. Neurosci. Abstr. 7: 778.

Crutcher, M. D., and M. R. DeLong (1983) Single cell studies of the primate putamen. II. Relations to direction of movement and pattern of muscular activity. Exp. Brain Res., in press.

DeLong, M. R. (1971) Activity of pallidal neurons during movement. J. Neurophysiol. 34: 414-427.

DeLong, M. R. (1973) Putamen: Activity of single units during slow and rapid arm movements. Science 179: 1240-1242. 
DeI song, M. R., and A. P. Georgopoulos (1979) Motor functions of the basal ganglia as revealed by studies of single cell activity in the behaving primate. In Advances in Neurology, L. J. Poirier, T. L. Sourkes, and P. J. Bedard, eds., pp. 131140, Raven Press, New York.

DeLong, M. R., and A. P. Genrgopoulos (1981) Motor functions of the basal ganglia. In Handbook of Physiology-Section 1: The Neruous System, Vol. II, Motor Control, Part 1, J. M. Brookhart, V. B. Mountcastle, and V. B. Brooks, eds., pp. 1017-1061, American Physiological Society, Bethesda.

DeLong, M. R., and P. L. Strick (1974) Relation of basal ganglia, cerebellum, and motor cortex units to ramp and ballistic limb movements. Brain Res. 71: 327-335.

Denny-Brown, D., and N. Yanagisawa (1976) The role of the basal ganglia in the initiation of movement. In The Basal Ganglia, M. D. Yahr, ed., pp. 115-149, Raven Press, New York.

Draper, I. T., and R. J. Johns (1964) The disordered movement in Parkinsonism and the effect of drug treatment. Bull. Johns Hopkins Hosp. 115: 465-480.

Evarts, E. V. (1974) Precentral and postcentral cortical activity in association with visually triggered movement. J. Neurophysiol. 37: 373-381.

Filion, M. (1979) Effects of interruption of the nigrostriatal pathway and of dopaminergic agents on the spontaneous activity of globus pallidus neurons in the awake monkey. Brain Res. 178: 425-441.

Flowers, K. (1975) Ballistic and corrective movements in an aiming task: Intention tremor and Parkinsonian movement disorders compared. Neurology 25: 413-421.

Georgopoulos, A. P., and M. R. DeLong (1979) Quantitative studies of neuronal activity in basal gnaglia during limb movements. Can. J. Neurol. Sci. 6: 79.

Georgopoulos, A. P., J. F. Kalaska, R. Caminiti, and J. T. Massey (1982) On the relations between the direction of twodimensional arm movements and cell discharge in primate motor cortex. J. Neurosci. 2: 1527-1537.

Hallett, M., and S. Khoshbin (1980) A physiological mechanism of bradykinesia. Brain 103: 301-314.

Hartmann-von Monakow, K., K. Akert, and H. Künzle (1978) Projections of the precentral motor cortex and other cortical areas of the frontal lobe to the subthalamic nucleus in the monkey. Exp. Brain Res. 33: 395-403.

Horak, F. B., and M. F. Anderson (1980) Effects of the globus pallidus on rapid arm movement in monkeys. Soc. Neurosci. Abstr. 6: 465.

Hore, J., and T. Villis (1980) Arm movement performance during reversible basal ganglia lesions in the monkey. Exp.
Brain Res. 39: 217-228.

Iansek, R., and R. Porter (1980) The monkey globus pallidus: Neuronal discharge properties in relation to movement. J. Physiol. (Lond.) 301: 439-455.

Kalaska, J. F., R. Caminiti, and A. P. Georgopoulos (1983) Cortical mechanisms related to the direction of two-dimensional aimed arm movements: Relations in parietal area 5 and comparison with motor cortex. Exp. Brain Res., in press.

Liles, S. L. (1978) Functional organization of neurons related to arm movement in the putamen. Soc. Neurosci. Abstr. 4; 46.

Liles, S. L. (1979) Topographic organization of neurons related to arm movement in the putamen. In Advances in Neurology, Vol. 23, T. N. Chase, N. S. Wexter, and A. Barbarbeau, eds., pp. 155-162, Raven Press, New York.

Liles, S. L. (1981) Activity of neurons in the putamen during movement and postural fixation of the arm against external loads. Soc. Neurosci. Abstr. 1: 778.

MacPherson, J. M., D. D. Rasmusson, and J. T. Murphy (1980) Activities of neurons in "motor" thalamus during control of limb movement in the primate. J. Neurophysiol. 44: 11-28.

Matsunami, K., and B. Cohen (1975) Afferent modulation of unit activity in globus pallidus and caudate changes induced by vestibular nucleus and pyramidal tract stimulation. Brain Res. 91: 140-146.

Petras, J. M. (1969) Some efferent connections of the motor and somatosensory cortex of simian primates and felid, canid and procyonid carnivores. Ann. N. Y. Acad. Sci. 167: 469505 .

Schmidt, E. M., R. G. Jost, and K. K. Davis (1975) Reexamination of the force relationship of cortical cell discharge patterns with conditioned wrist movements. Brain Res. 83: 213-223.

Strick, P. L. (1976) Activity of ventrolateral thalamic neurons during arm movement. J. Neurophysiol. 39: 1032-1044.

Thach, W. T. (1978) Correlation of neural discharge with pattern and force of muscular activity, joint position and direction of intended next movement in motor cortex and cerebellum. J. Neurophysiol. 41: 654-676.

Whittier, J. R. (1947) Ballism and subthalamic nucleus (nucleus hypothalamicus; corpus Luysi). Arch. Neurol. Psychiatry 58: 672-692.

Whittier, J. R., and F. A. Mettler (1949) Studies of the subthalamus of the rhesus monkey. II. Hyperkinesia and other physiologic effects of subthalamic lesions with special references to the subthalamic nucleus of Luys. J. Comp. Neurol. 90: 319-372. 